\title{
Constant and random practice on learning of volleyball serve
}

\section{Prática constante e aleatória na aprendizagem do saque do voleibol}

\section{Madson Pereira Cruz \\ Guilherme Menezes Lage ${ }^{1}$ \\ Patrick Costa Ribeiro-Silva ${ }^{1,2}$ \\ Thiago Fernandes Neves \\ Cíntia de Oliveira Matos \\ Herbert Ugrinowitsch ${ }^{1}$}

Abstract - The type of practice can influence what is learned from a motor skill. The aim of this study was to investigate the effects of the constant and random practice on the learning of Generalized Motor Program and parameters of the volleyball serve. The sample was composed of 20 children between 10 and 12 years old. The participants performed a pre-test whose score was adopted to counterbalance two groups $(n=10)$, random practice and constant practice. During the acquisition phase, the random group performed 252 serves from three different positions, always indicated at the end of each serve, and the constant group performed all serves from only a specific position. The retention test showed that both groups learned the Generalized Motor Program, but random practice conducted to higher parameterization learning, resultant from the variable of practice. During practice of a sport motor skills, although the constant and random practice improve the learning of Generalized Motor Program, only the random practice improves learning of parameters of the motor skill.

Key words: Motor activity; Parameters; Volleyball.

Resumo - O tipo de prática pode influenciar o que é aprendido de uma habilidade motora. Objetivou-se investigar os efeitos da prática constante e aleatória na aprendizagem do Programa Motor Generalizado e parâmetros do saque do voleibol. A amostra foi composta por 20 crianças entre 10 e 12 anos. Os participantes realizaram um pré-teste, cujo escore foi utilizado para contrabalançar dois grupos $(n=10)$, prática constante e aleatória. Durante a fase de aquisição, o grupo aleatório realizou 252 saques de três posiçôes diferentes, sempre indicada ao final de cada saque e o grupo controle realizou todos os saques somente de uma posição especifica. O teste de retenção mostrou que ambos os grupos aprenderam o Programa Motor Generalizado, mas a prática aleatória conduziu para uma melhor aprendizagem dos parâmetros, resultante da prática variada. Durante a prática de habilidades motoras esportivas, apesar de as práticas constante e aleatória melhorarem a aprendizagem do Programa Motor Generalizado, somente a prática aleatória melhora a aprendizagem dos parâmetros da habilidade motora.

Palavras-chave: Atividade motora; Parâmetros; Voleibol.
1 Universidade Federal de Minas Gerais. Belo Horizonte, Minas Gerais. Brazil.

2 Faculdade de São Lourenço. UNISEPE. São Lourenço, MG. Brazil

Accepted: October 18, 2018 Received: April 26, 2018 


\section{INTRODUCTION}

Practice schedule improves motor skill acquisition and the variable practice is one of the most investigated structures of practice. The variable practice consists of variations in the characteristics of the context $t^{1}$ or changes in the practiced motor skill ${ }^{2}$. The studies regarding the effect of the practice schedule in the acquisition of motor skills started by the 1970 ' $\mathrm{s}^{3}$ comparing block versus random practice and went through the 2000's ${ }^{4-6}$. Although some inconsistent results have been found, the evidence pointed to a better learning in random practice when compared to blocked practice.

Another structure of the practice is the constant practice, which requires the execution of a unique criterion-based skill. A low status was ascribed to constant practice after Shea and Morgan ${ }^{3}$, based on the view that the repetitive characteristic of this structure of practice promotes a low level of learning. However, from the late 1990s, studies brought back constant practice to the scene investigating it effects on learning in a new perspective $\mathrm{e}^{7-10}$. Lai and Shea ${ }^{9}$ were the first to propose that constant practice promotes performance consistency trial-to-trial, characteristic that facilitates the learning of the movement structure (i.e., generalized motor program - GMP). Moreover, the variable practice leads to instability trial-to-trial during practice, improving the ability to select the skill parameters ${ }^{7,8,10}$.

These assumptions were tested with a simple laboratory task (e.g., ${ }^{7-}$ ${ }^{11}$ ), which required pressing four alphanumeric keyboards of a computer keys in pre-established order manipulating relative time or total target time. The results have shown that constant practice improves learning of $\mathrm{GMP}^{9,10}$ and variable practice improves learning of parameters ${ }^{7,10}$. A next step in the study of the role of constant and variable practice is to verify if these effects in the learning of GMP and parameter are also observed in complex motor skills.

Although some studies compared random versus blocked practice with complex motor skills ${ }^{12}$, to our knowledge, no studies have investigated the effects of practice schedule in learning of GMP and parameterization with complex sports motor skills. Testing these presupposes on a complex sport skill is important since the principles originated on simple motor skills can be not generalized to complex motor skills ${ }^{13}$. So, this study investigated the assumptions of what is learned (i.e., GMP or parameterization) when inexperienced participants practice under different types of structure of practice on learning of the volleyball serve. From the results obtained in the studies with simple laboratory tasks, our hypothesis is that the constant practice will improve learning of the GMP and variable practice will improve learning of skill parameters.

\section{METHODOLOGICAL PROCEDURES}

\section{Sample}

The sample consisted of 20 children aged between ten and twelve years 
old (five boys and fifteen girls: $M=10.92 \pm 0.82$ ) of both sexes and without experience in the task. All participants as well their parents were requested to read and sign an informed consent before taking part in the experiment. The participants were distributed into two groups $(n=10)$, random practice and constant practice and all the procedures were approved by the Ethical Committee of the Federal University of Minas Gerais (CAAE 48354515.4.0000.5149).

\section{Task and Instrument}

The task of this experiment consisted of performing the volleyball tennis serve (Figure 1) from one side of the court aiming to reach the target bull's-eye positioned on the floor on the opposite side of the court.

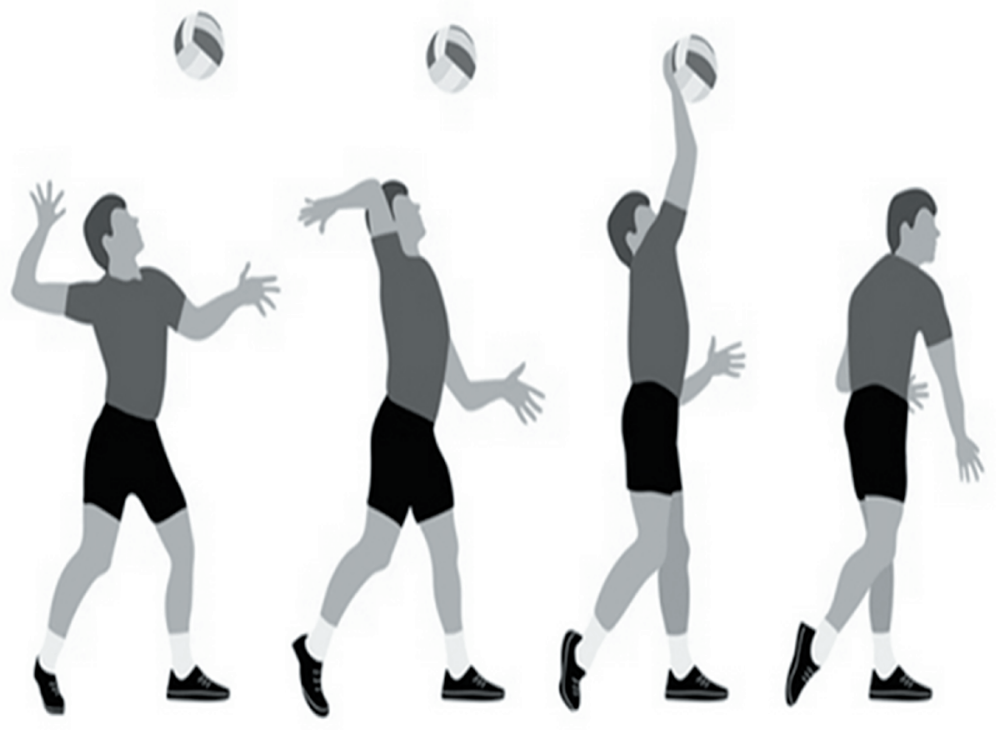

Figure 1. Illustration of the volleyball tennis serve. Fonte: SportSG (https://www.myactivesg.com)

Taking into account the differences between experimental condition, it was adopted similar measures to those in laboratory situation in previous studies ${ }^{7,9}$. Two instruments were adopted, one to measure the structure of control (GMP) learning and another to measure the parameters learning. Since the GMP represents relative time and sequence of the motor skill ${ }^{14}$, the analysis of the GMP was carried out by a checklist of the Meira Jr. ${ }^{15}$, validated by $\mathrm{Costa}^{16}$, which consisted of the analysis of the Initial Position, Ball Throwing, Hitting, and Finalization. The total score ranged from 9 to 27 points for analysis of the GMP. The analysis of the parameterization was measured by performance accuracy concerning the target bull's eye, ranged from 2 to 28 points for analysis of the parameterization (Figure 2), reflecting the ability of the selected parameters on each serve (e.g., force and direction). Both instruments were adopted in Santos-Naves ${ }^{17}$. One

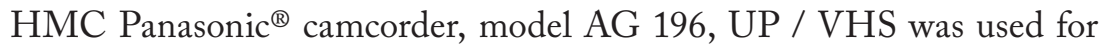
recording the serve, volleyball balls and ribbons for demarcation of the court areas in direction to the target and the service box. 

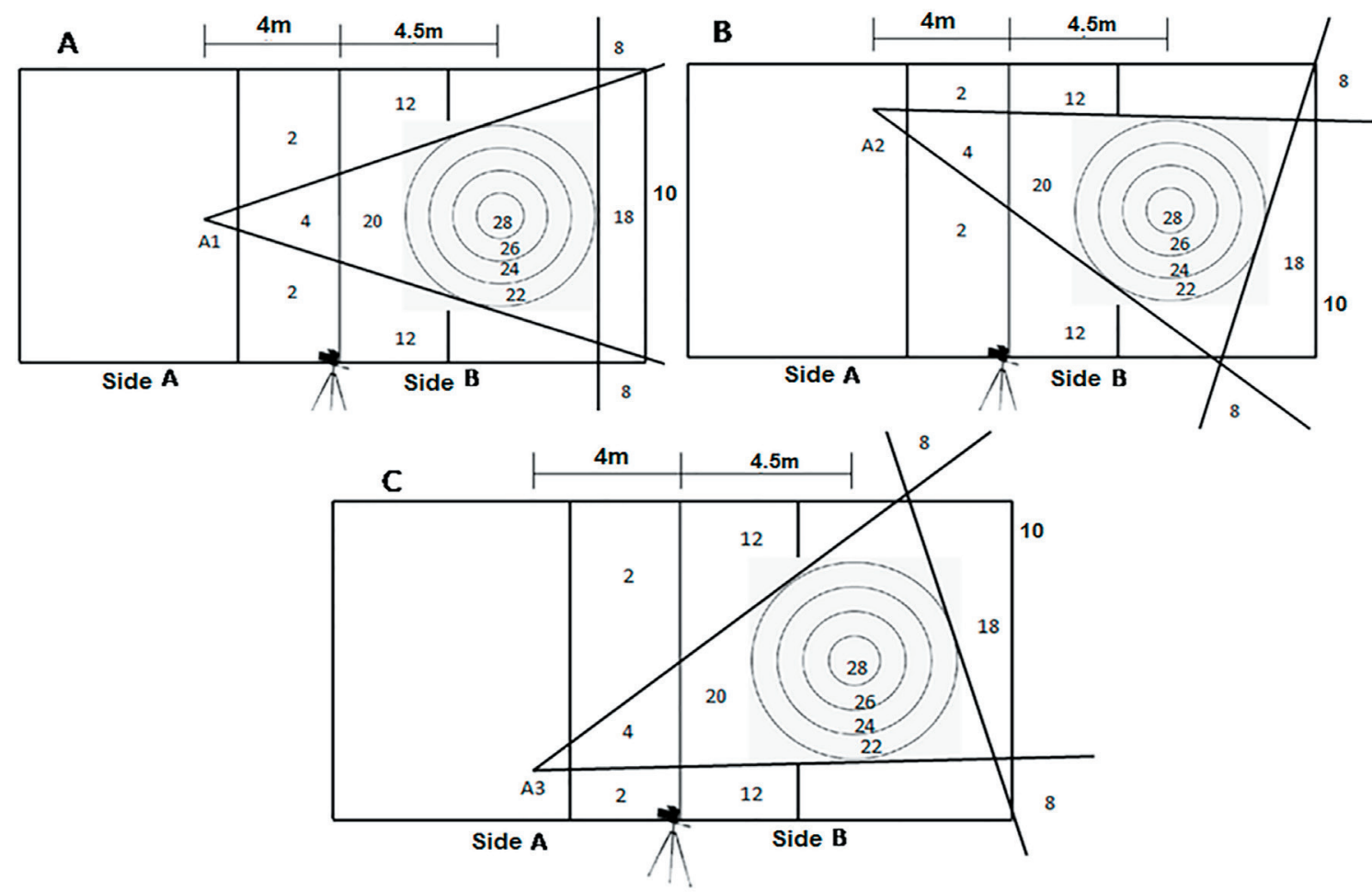

Figure 2. Instrument to evaluation of the withdrawal score performance, adapted from the instrument used by Santos-Naves ${ }^{17}$.

The serves were performed from one line marked on the side "A" of the court $4 \mathrm{~m}$ from the net. The target was lied down on the side "B" of the court and its center was $4.5 \mathrm{~m}$ away from the net. There were three serve positions that were adopted in accordance with the group. Each position was bounded by two lines from the center of the serve position until the target zone and remained outside the court. The ball that reached the target bull's-eye received 28 points, and the score diminished as the ball was far from the center of the target. Moreover, the ball that reached the floor in the target direction represented an error on force control and received higher score than the ball that reached the floor to the right or the left of the target. So, the lowest score was 2 points when the ball did not pass the net and was not to the target direction.

\section{Experimental Design}

The participants were distributed into random practice group (RG) and constant practice group (CG) according to the performance score on the serve obtained in the pre-test. This procedure was adopted to ensure that both groups should start the experiment with similar performance accuracy. In the pre-test, participants performed 15 serves from area A1 and performance score was noted by one researcher. Forty-eight hours after the pre-test, the acquisition phase started consisting of six sessions with 42 serves, with a total of 252 serves. The retention test was performed 48 hours after the last session of the acquisition phase, and it was performed in the same conditions of the pre-test. Moreover, both pre and post-tests 
were recorder for later analysis. We spent three weeks collecting data for each participant, and 20 weeks for collecting all the participants.

\section{Procedure}

The first-day standardized instructions on the pretest were provided. A video with one experienced participant performing the volleyball serve was shown five times to the volunteers before starting the test. The same procedure was repeated during the first three sessions of the acquisition phase. In the pre-test, each participant performed 15 serves that were recorded for posterior analysis and the score was noted. Two days after pre-test, acquisition phase began.

The participants were called to volleyball court in pairs and the order to perform the serve was counterbalanced across sessions. Upon arriving at the collection site, participants received instruction in accordance with the group in which they were allocated. The CG performed all the trials from region $\mathrm{A} 1$ and the $\mathrm{RG}$ was informed the regions to perform every trial five seconds after the previous trial. After every trial, the feedback about the location that the ball touched the ground was available. There was no feedback about movement pattern. Two researchers performed the movement analysis (i.e., GMP measure) and the score of the performance (i.e., parametrization measure). Both tests showed reliability higher than $85 \%$, which is in accordance to Thomas, Nelson and Silverman ${ }^{18}$.

\section{Data analyses}

Data analysis was performed over accuracy (average) and consistency (standard deviation) of both, GMP and parameter by two-way ANOVA (Groups $2 \times 2$ Tests) with repeated measures on the second factor. When necessary, the post hoc LSD was adopted for pair comparisons. The effect size was interpreted as .01 (small), .06 (moderate) and 0.12 (large) ${ }^{19}$. The level of significance adopted in the study was $p \leq 0,05$.

\section{RESULTS}

The data was organized in blocks of 15 trials from both, pre-test and retention-test.

Figure 3a shows that GMP improved accuracy significantly from pre-test to post-test $F(1 ; 18)=42,01, p=0,001, \eta^{2}=0,7$. There was neither significant difference between groups $F(1 ; 18)=0,001, p=0,95, \eta^{2}=0,01$ nor main interactions $F(1 ; 18)=1,55, p=0,22, \eta^{2}=0,07$.

Figure $3 \mathrm{~b}$ shows that GMP consistency did not change significantly with practice $F(1 ; 18)=2,68, p=0,11, \eta^{2}=0,12$. Moreover, both groups had similar consistency $F(1 ; 18)=0,412, p=0,52, \eta^{2}=0,02$ and there was no main interactions $F(1 ; 18)=1,4, p=0,25, \eta^{2}=0,07$.

Figure $4 \mathrm{a}$ shows that parameter accuracy had significant interaction between groups and tests $F(1 ; 18)=9,66, p=0,006, \eta^{2}=0,34$. The post hoc detected that the RG had higher accuracy than the $\mathrm{CG}$ on retention test 
$(p=0,03)$. Moreover, RG increased accuracy from the pre-test to the retention test $(p=0,03)$. There was neither effect for tests $F(1 ; 18)=0,02, p=0,88$, $\eta^{2}=0,01$, nor for groups $F(1 ; 18)=1,65, p=0,21, \eta^{2}=0,08$.

Figure $4 \mathrm{~b}$ shows that $\mathrm{CG}$ had significantly higher parameter consistency than $\operatorname{RG} F(1 ; 18)=5,155, p=0,03, \eta^{2}=0,22$. There was no significant difference between testes $F(1 ; 18)=0,22, p=0,64, \eta^{2}=0,01$ and also there was no main interactions $F(1 ; 18)=0,96, p=0,33, \eta^{2}=0,05$.
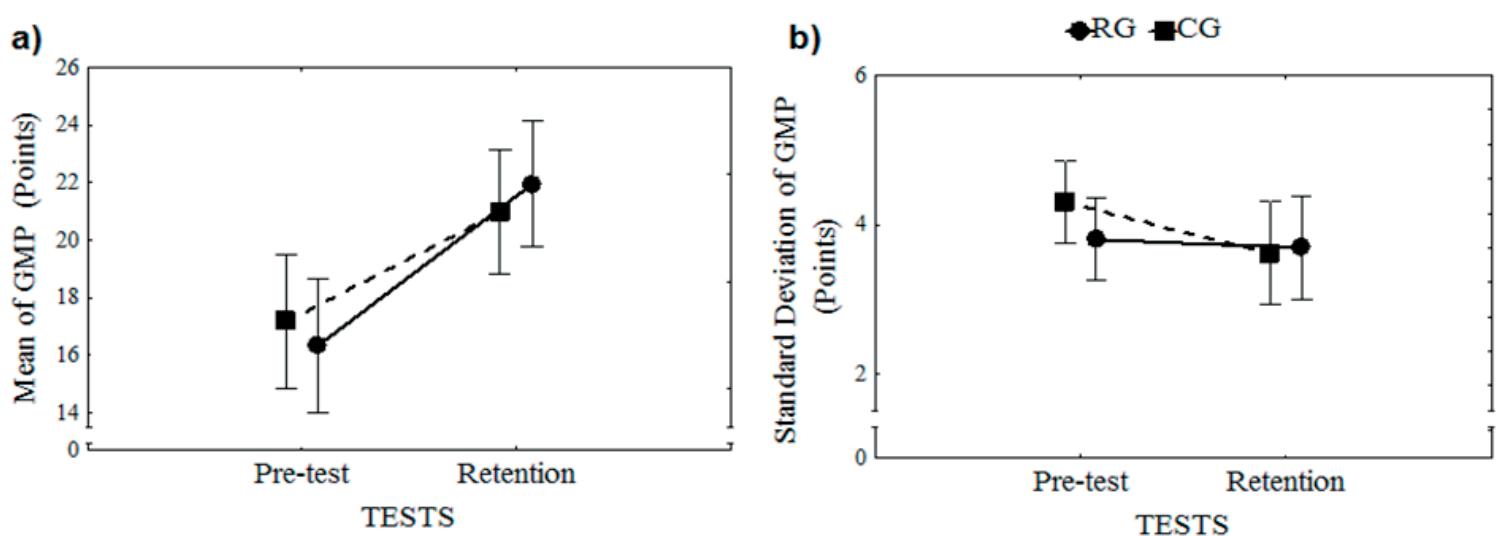

Figure 3. Analyses of GMP of the volleyball serve during Pre-test and Retention test. a-shows the accuracy of the GMP. b-shows the consistency of the GMP. The vertical bars denote the confidence in

b)
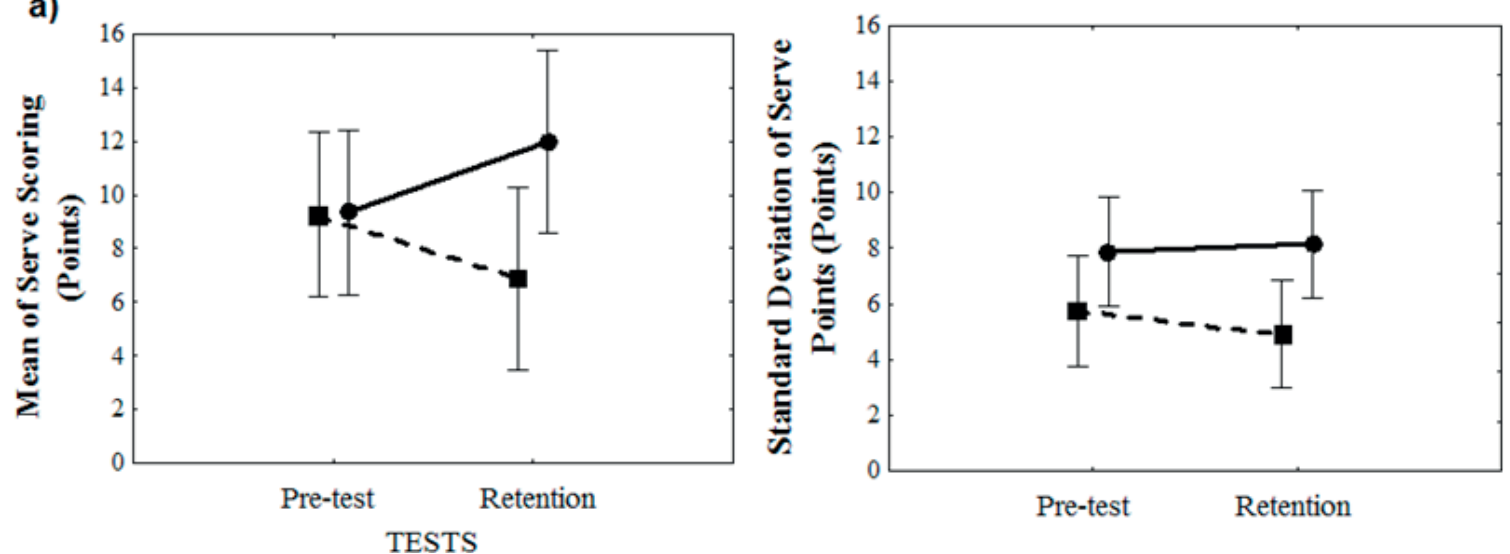

Figure 4. Analyses of parameters in the serve. a-shows parameters accuracy of serving score. b-shows parameters consistency of serving score. The vertical bars denote the confidence interval in $95 \%$.

\section{DISCUSSION}

The studies about structure of practice have shown that constant practice is associated with better learning of GMP and random practice is associated with the parameterization learning, particularly when applied simple laboratory tasks. Investigation of this subject applied to complex sports skills have been not found. The present study tested the hypothesis that constant practice should improve learning of the GMP and random practice the learning of parameters in a complex sport skill. The results confirmed our hypothesis partially, considering that only the random practice effect on parameterization was observed but both structures of 
practice improved GMP.

Studies that applied laboratory task $\mathrm{k}^{9,10}$ have found that constant practice promotes better learning of the GMP than random practice. Without trial-to-trial changes in parameters, an attentional focus oriented to the movement's components favors the better learning of GMP in the constant practice $^{7}$. However, in the present study, a different result was found. The analysis of the GMP accuracy during retention test showed the same level of learning for both conditions of practice. The development of a GMP for a more complex skill, which demands the coordination of several degrees of freedom, requires more effort and information-processing engagement than simple laboratory tasks ${ }^{13}$. It is possible that, at least in the initial phase of the learning, the learners oriented their attention to the components of the movement to guarantee some level of stability in detriment of the parameter accuracy. Stability in this task requires throw the ball accurately and organize arm backswing and attack the ball in the right time and space. This high demand of the task should direct the attention to these components of the task.

Opposite results were found on the analysis of the parameterization, and they are similar to those from applied laboratory tasks ${ }^{7,11}$, and they are different to the proposal of Wulf and Shea ${ }^{13}$. Random practice produced to trial-to-trial changes in parameters inducing to better parameterization learning than constant practice. Such results allow us to speculate that, even when the tasks have a higher number of degrees of freedom and requires learning both, GMP and parameters, the random practice improves parameters accuracy. The random practice ranging parameters may have improved engagement in the task ${ }^{20-22}$ and strengthened the schemas related to the task ${ }^{14,23}$, which did not happen with the constant practice. Possibly, the random practice leads to a greater active preparation than the constant practice ${ }^{24}$.

However, the constant practice provided greater parameters consistency than random practice. The random practice leads to instability inter-trials during practice ${ }^{7,10}$, resulting in lower consistency during retention test. On the other hand, the constant practice provided greater consistency intertrials, which was observed in the small variability. Even so, this result supports the hypothesis that greater engagement of random practice combined with the improvement of the schemas assists in the learning of the parameters and promotes higher parameters accuracy than constant practice. It is interesting to test if these results will be replicated with variation of GMP. Although random practice does not improve consistency on serving score, it promotes accuracy. This relationship between higher accuracy with low consistency should be investigating in future studies. Moreover, since the level of fundamental motor skills can influence the learning of sport motor skills, variation among samples was negligible and should be investigated in future studies. At last, since the time for collecting data of each participant lasted three weeks, it was nearly impossible to control practice beyond experimental situation and watching games on TV or gymnasium. 


\section{CONCLUSION}

In conclusion, during practice of a sport motor skill, both constant and random practice improves the learning of GMP. However, only random practice improves learning of parameters of the motor skill.

\section{COMPLIANCE WITH ETHICAL STANDARDS}

\section{Funding}

This research did not receive any specific grant from funding agencies in the public, commercial, or not-for-profit sectors. This study was funded by the authors.

\section{Ethical approval}

Ethical approval was obtained from the local Human Research Ethics Committee - Ethical Committee of the Federal University of Minas Gerais (CAAE 48354515.4.0000.5149), and the protocol was written in accordance with the standards set by the Declaration of Helsinki.

\section{Conflict of interest statement}

The authors have no conflict of interests to declare.

\section{Author Contributions}

Conceived and designed the experiments: MPC, HU. Performed the experiments: MPC, PCRS and TFN. Analyzed the data: MPC, PCRS and TFN. Contributed reagents/materials/analysis tools: MPC, GML, PCRS, TFN, COM and HU. Wrote the paper: MPC, GML, PCRS, TFN, COM and HU.

\section{REFERENCES}

1. Del Rey P, Wughalter EH, Whitehurst M. The effects of contextual interference in females with varied experience in open sport skill. Res Q Exerc Sport 1982;53(2):108-15.

2. French KE, RinkJE, Werner PH. Effects of contextual interference on retention of three volleyball skills. Percept Mot Skill 1990;71:179-86.

3. Shea JB, Morgan RL. Contextual interference effects on the acquisition, retention, and transfer of a motor skill. J Exp Psychol 1979;5(2):179-87.

4. Fialho JVAP, Benda RN, Ugrinowitsch $H$. The contextual interference effect in a serve skill acquisition with experienced volleyball players. J Hum Mov Stud 2006;50:65-78.

5. Saemi E, Porter JM, Varzaneh AG, Zarghami M, Shafinia P. Practicing along the contextual interference continuum: a comparison of three practice schedules in an elementary physical education setting. Kinesiology 2012;44(2):191-8.

6. Wright DL, Shea CH. Manipulating generalized motor program difficulty during blocked and random practice does not affect parameter learning. Res Q Exerc Sport 2001;72(1):32-8.

7. Lage GM, Alves MAF, Oliveira FS, Palhares LR,Ugrinowitsch H, Benda RN. The combination of practice schedules: effects on relative and absolute dimensions of the task. J Hum Mov Stud 2007;52:21-35. 
8. Lai Q, Shea CH, Wulf G, Wright DL. Optimizing generalized motor program and parameter learning. Res QExerc Sport 2000;71(1):10-24.

9. Lai Q Shea $\mathrm{CH}$. Generalized motor program (GMP) learning: effects of frequency of knowledge of results and practice variability. J Mot Behav 1998;30(1):51-9.

10. Shea $\mathrm{CH}$, Lai Q, Wright DW, Immink M, Black C. Consistent and variable conditions: effects on relative and absolute timing. J Mot Behav 2001;33(2):139-52.

11. Januário MS, Ugrinowitsch H, Lage GM, Vieira MM, Benda RN. Effect of the combination of different practice schedules on acquisition of motor skills. Rev Bras Cien Esporte 2014;36:5758-5773.

12. Hebert EP, Landin D, Solmon MA. Practice schedule effects on the performance and learning of low- and high-skilled students: an applied study. Res Q Exerc Sport 1996;67(1):52-8.

13. Wulf G, Shea CH. Principles derived from the study of simple skills do not generalize to complex skill learning. Psychon Bull Rev 2002;9(2):185-211.

14. Schmidt RA. A Schema theory of discrete motor skill learning. Psychol Rev 1975;82(4):225-60.

15. Meira Jr, CM. Validating a checklist for qualitative analysis of volleyball serve. Motriz: J Phys Ed 2003;9(3):153-60.

16. Costa CLA, Bandeira PFR, Matos CO, Cruz MP, Ugrinowitsch H. Construct validity and reliability of a checklist for volleyball serve analysis. Rev Bras Cineatropom Desempenho Hum 2017;20(1):95-101.

17. Santos-Naves SP, Benda RN, Junqueira AHM, Alves GM, Velloso AP, Ugrinowitsch $\mathrm{H}$. The effect of distributed demonstrations in the volleyball serve learning. Rev Bras Edu Fís Esporte 2014;28(4):629-39.

18. Thomas JR, Nelson JK., Silverman, S. Research Methods in Physical Activity. Champaign, IL: Human Kinetics Publishers; 2011.

19. Green, SB. Salkind NJ. Using SPSS for Windows and Macintosh. Analyzing and Understanding Data: Pearson/Prentice Hall; 2008.

20. Lage GM, Ugrinowitsch H, Apolinário-Souza T, Vieira MM, Albuquerque MR, Benda RN. Repetition and variation in motor practice: a review of neural correlates. Neurosci Biobehav Rev 2015;57:132-41.

21. Lin CHJ, Fisher B, Winstein, C. Contextual interference effect: elaborative processing or forgetting-reconstruction? A post hoc analysis of transcranial magnetic stimulation-induced effects on motor learning. J Mot Behav 2008;40(6):578-86.

22. Shea JB, ZimnyJB. Context effects in memory and learning movement information. In: Magill, R.A. Memory and Control of Action: ed. North-Holland Publishing Company; 1983. p. 345-366.

23. Moxley SE. Schema: the variability of practice hypothesis. J Mot Behav 1979;11(1):65-70.

24. Cross E, Schmitt P, Grafton S. Neural substrates of contextual interference during motor learning support a model of active preparation. J Cog Neuro 2007;19(11):1854-71.

\section{CORRESPONDING AUTHOR}

Herbert Ugrinowitsch Universidade Federal de Minas Gerais.

School of Physical Education, Physiotherapy and Occupationa Therapy.

Av. Antônio Carlos, 6627, CEP 31270-901, Pampulha, Belo Horizonte, Brazil Email: herbertu@ufmg.br 